\title{
Work-Family Balance of Managerial Employees: A Study in a Sri Lankan Firm
}

\author{
M.M.U. Perera \\ BSc HRM Special Scholar \\ Faculty of Management Studies and Commerce, \\ University of Sri Jayewardenepura \\ mmuperera@yahoo.com
}

\begin{abstract}
Work-family balance of managers is critical for organizational success as their inability to have the balance can lead to significant bad consequences. An empirical study was carried out to achieve three objectives: (1) to investigate whether the managerial level employees consider the balance between work life and family life as important; (2) to investigate the reasons for their perceptions; and (3) to investigate as to how the managers who work in the organization under the study maintain work-family balance. The qualitative method was adopted and one particular private company was selected for the study purpose. 15 managers who are married and having a family life were considered for the purpose of collecting data to achieve the research objectives. The interview technique was used along with a carefully prepared interview checklist in order to collect data. The findings reveal that to have work-family balance is very important because the life has a family aspect other than the work aspect; therefore there is a need of avoiding work-family conflicts. There are many ways of maintaining the balance between work-life and family life followed by the managers and they have been specifically mentioned in the study.
\end{abstract}

Key Words: Managers, Work-Family Balance, Work-Family Conflict 


\section{Introduction}

The workforce of the organization is being treated as the key resource among all other resources due to its unique and exclusive features and this enables the organization to gain a sustainable competitive advantage over competitors in the dynamic business context. The managerial employees of a firm play a strategic role in driving the business and they are loaded with many work goals to be achieved. On the other hand there are various sets of personal life goals too to be achieved (Aswathappa, 2017). Therefore the identification of practice of balancing the family life and work life in managerial level employees is essential since both depend on each other, family life has an impact on working life and working life has an impact on personal life. At present many people who are working are compelled to play a dual role in their lives whether they like or not. The demands from the workplace have increased in each employee's role and the demands from the family life are on the other hand. The needs of the job and the needs of the family may often interfere with one another, where it is possible to consider work life and family life as the two sides of a single coin. Many employees carry negative and positive feelings from home to work and vice versa. Adults as working employees have two very important areas of their lives that require a delicate balance between family life and work life. When conflicts occur between these two areas both sides tend to suffer producing unfavourable results to both work and family.

Achieving the balance between work life and family life depends on different factors to different people. Some will want to devote equal amount of time and energy to family and work whereas others will not want. The concept of family has been a very strong feature in the Sri Lankan history. The family plays a vital role in determining the behaviour of the society. With the changing demands of the environment, life styles of people have become more complex to manage. The past role of the manager too has changed and become more complex owing to new job demands which come from increased competition, new growth plans of the business, and competition among managers to get promoted to top positions of the organization which are limited in number. Most of the managers do not have time to spend with their families, neighbours, friends, and society. Also they have less time to spend for leisure activities that please their minds. The result is the occupational stress which may lead to some mal practices such as being addicted to alcohol, smoking, illegal affairs and others. Consequently job satisfaction, motivation to work, and job performance get impaired. Family problems may get increased requiring the relevant managers to be absent or ask for leave. These causes coupled with increased workloads will result in increasing employee grievances. According to Opatha (1994) a grievance means any discontent or dissatisfaction arising from a feeling or a belief of injustice felt by an employee or a group of employees in connection with the work environment.

General observations reveal that there are some managers in Sri Lankan organizations who have work-family conflicts. These conflicts result in reducing organizational productivity. Concern on productivity is vital (Akuratiyagamage and Opatha, 2004). Thus studying workfamily balance is worth and interesting. 
Research objectives of this study are: (1) to investigate whether the managerial level employees consider the balance between work life and family life as important; (2) to investigate the reasons for their perceptions; and (3) to investigate as to how the managers who work in the organization under the study maintain work-family balance.

\section{Method}

This research paper is an empirical study done by using the qualitative method. One particular private company was selected for the study purpose. 15 managers who are married and having a family life were considered to collect data to achieve the research objectives. In order to collect data the interview technique was used along with a carefully prepared interview checklist. The researcher personally went to meet the selected 15 managers to collect data. All the 15 managers were cooperative and therefore thick descriptions could be done. The interview checklist is given in Appendix 1. Appendix 2 presents the exact responses given by two male managers and one female manager.

\section{Work-Family Balance}

There are many different ways to define and discuss balance but most seem to include the notions of flexibility (Hill, Hawkins, Ferris, and Weitzman, 2001), sustainability (Van and Vos, 2002), and juggling (Brown, 2004). According to Limoges (2003), work-life balance is "primarily a matter of deciding when to hold on and when to let go". It has been defined as satisfaction and good functioning at work and at home with a minimum of role conflict (Clark, 2000). It is characterized by the absence of unacceptable levels of conflict between work and non-work demands (Greenblatt, 2002). Opatha (2019, p. 140) defines:

"Work-family balance is the degree to which a particular employee fulfils demands coming and responsibilities arising from his or her employment and family. The degree of fulfilling can be high, moderate, or law. It involves meeting commitments at both work and family by the employee through the use of his or her time, effort, capabilities, and other strategies."

According to the above quotation, work-family balance has to be established and maintained through the use of manager's time, effort, capabilities, and other strategies. According to the model developed by Senecal, Vallerand, and Guay (2001) which is about antecedents and outcomes of work-family conflict, feeling valued by one's partner, feeling autonomy-supported by one's employer, motivation toward family activities, motivation toward work, and family alienation are antecedents of work-family conflict and feelings of emotional exhaustion are outcomes of work-family conflict. High levels of self-determined family and work motivation are two factors which are contributory to reduce family alienation, which in turn influences on reducing work-family conflicts experienced by employees. The level of employer support for out-of-work responsibilities and activities has a crucial impact on the extent to which graduates experience conflict between work and home, furthermore it is negatively linked to experience of work conflict, and has a close positive relationship with organizational commitment (Sturges and Guest, 2004). Opatha and Perera (2017) did an empirical study about the determinants of work-family balance of 
accounting professionals in Sri Lanka and accordingly the determinants include 23 factors. They are:

1. Understanding the strategies available for WFB,

2. Commitment to work

3. Leadership style of the organization

4. Distance between home and workplace

5. Workload including targets

6. Superior's willingness to delegate work to subordinates

7. Organization's willingness and effort to train the subordinates

8. Time management including clear division of one's time for both work and family life

9. Nature of spouse (selecting a suitable partner and mutual understaning, patience and support from the spouse)

10. Planning oneself based on one's SWOT without blindly following others

11. Time allocation for family

12. Management of stress

13. Corporation from co-workers

14. Positive attitude towards family

15. Adaptability

16. Flexible work arrangements (flex time, telecommuting, part time, compressed work schedules, job sharing etc.)

17. Leave arrangements

18. General services (e.g. child care and dependent care assistance, counselling etc.)

19. Resources and facilities to perform the job

20. Availability of support from relatives

21. Possibility of employing a servant

22. Understanding of the demands, responsibilities and expectations of all the relevant parties at work and family

23. Availability of getting advice from right persons and materials

Furthermore they found that the most important factors were 1, 8, and 9 respectively.

\section{Views about the Importance of Maintaining the Balance}

All the managers who participated in sharing their views have no issue in accepting the importance of maintaining a good balance between their professional life and the personal life. There is no second thought or argument about this fact. Furthermore, only six of them admitted that they are maintaining a fair balance between their professional life and the personal life whilst other nine managers admitted that they are not maintaining a fair balance.

The participants for the interview brought up elaborated their views. According to the thoughts, there are two main types of responsibilities that they have to fulfill, mainly the professional obligations and the other being the social and family related obligations. They are aware that as managers, playing an important role in the company, at certain times they 
need to be dedicated, be ready to work long hours, and also be ready to come to work sometimes on weekends. Apart from this the foreign assignments they need to attend to, the deadlines that they need to meet, the sensitive group of subordinates who are reporting to them and the vast responsibility they have on their shoulders make their job an important one. They are fully aware of the job demands they have from the organization's side, and they are also aware they need to be excellent in their jobs if they need to be successful managers in the organization.

On the other hand, talking about their personal and private lives, they mentioned that they have acted a totally different role. Being a loving husband or wife, being a father or mother who is caring for the family and the children, the role that they have to perform as a son or daughter to the family are also crucial. They have viewed that having a personal satisfaction as a person is very important for them. Most of them viewed that they are engaged in a profession because of their family, and because of the obligations that they need to fulfill to their family members. Due to these reasons, they think that having a fair balance between the work life and family life is very important as a person who is handling a responsible position of the company, which ultimately leads to being an effective, efficient and useful person to the organization, to their family, and to the society as well.

\section{The Ways of Maintaining the Balance by the Managers}

As mentioned in the previous section, out of the fifteen managers who participated in this face-to-face interview, only six stated that they have been able to maintain a fair balance. The rest of the managers stated that they have being struggling to manage. At the same time the managers who had confidently viewed that they are successful in balancing the work life and family life, and further mentioned that they have also failed at least once in having a good balance.

Among the various methods and tactics, which these managers use and think better to be used, being smart on the job itself is one thing which will help a manager to maintain the balance. Also at the same time being able to plan is important. They stressed that as managers they need to maintain a proper plan about each of their activities. They stated that even in one's personal life it is important to plan the key events. Apart from planning, being well organized, having a good time management discipline, and the ability to delegate the activities to right subordinates without fear have helped them to maintain the balance.

Furthermore, having access to the required resources in an appropriate capacity is another way. Having a clear job description is another method. Because of a clear job description, to identify the number of duties and job responsibilities is possible. Also two managers clearly stated that their ability of saying 'yes' to certain things and 'no' to the things which are beyond their control and what they cannot perform within a stipulated time period has contributed to have the balance in a great extent.

When talking about the family related responsibilities, they clearly said that they need to have a fair knowledge and an understanding about each of the family members and also 
their demands. This is another requirement that has to be performed to have the balance. All the participants for this study except two firmly appreciated the support given by their family members. Especially they stated that their wives even being employed give a massive and marvelous support and without which they would have failed. Further the understanding between the husband and wife and the understanding they have among the in-laws, parents and other family members back managers to achieve the balance. They see the sacrifice made from their spouses regarding certain family related issues and not giving the pressure as instrumental.

Female managers (manageresses) viewed that having a good understanding of levels of job stress and family stress are important and they faced a high stress level. They were supposed to perform the traditional home related activities such as cleaning, preparing meals, and looking after children. Eleven managers agreed with that the work stress and the family stress exist, and to control both stresses is a must, and therefore their ability to manage stresses is contributory to have the balance. The manageresses believe that if they have the capacity, good educational levels, competencies, the right attitude and being smart, to balance the work life and family life is possible, not impossible.

Almost all the managers think that the immediate superior's attitude towards work and the support from him or her contribute to a greater extent in maintaining the work-family balance. Some managers believed that it is not only the superior's support, but they themselves need to know how to balance and engage in balancing. Not having a superior who is a workaholic and not giving an example of the balance is non-contributory.

\section{Concluding Remarks}

Work-family balance is a critical phenomenon in an organization. It is about the employees' ability to meet his or her demands and responsibilities with regard to the job and the family. Without the balance between the work life and family life, there can be work-family conflicts which will result in many unfavourable consequences such as high stress, job dissatisfaction, impaired job performance and grievances. Managers are critical employees for the organization's success as they plan, organize, staff, direct, and control business activities. Without the right contribution of the managers the organization is indeed not in a position of accomplishing its vision, mission and goals.

The empirical study carried out quantitatively revealed that to have work-family balance is very important from the point of the managers studied. It is very important because it causes badly the life as it has aspects other than the job. The ways or strategies of maintaining work-family balance by the managers considered for the study include:

Being smart on the job itself

Being able to plan each job activity

To plan the key events of the personal life

Being well organized, having a good time management discipline, and the ability to delegate the activities to right subordinates without fear 
To have a fair knowledge and an understanding about each of the family members and also their demands.

The support given by their family members

To have a right understanding between the husband and wife and the understanding they have among the in-laws, parents and other family members

The sacrifice made from their spouses regarding certain family related issues and not giving the pressure

A good understanding of levels of job stress and family stress

Their ability to manage stresses

The immediate superior's attitude towards work and the support from him or her

This study has limitations. The study was limited to only one private sector firm. Hence generalizability of the findings may not be possible. There may be firms which use certain strategies which are different from the strategies being followed by the managers and the organization under this study. Strategies such as telecommuting, compressed workweek, job sharing, part-time employment, shift works, and flexi-hours may be some examples. Similar studies can be carried out with regard to other types of employees such as operative employees, sales and marketing employees and manufacturing employees. The reliability of the data collected may not be at high level owing to the reluctance of disclosing maters of personal nature.

\section{References}

Akuratiyagamage, V.M. and Opatha, H.H.D.N.P. (2004), Grievances of middle managers: an empirical investigation into perceptions of commercial bank branch managers in Sri Lanka, Journal of Management Research, Faculty of Management Studies, University of Delhi, 4: 2, August, pp. 99-112.

Aswathappa, K. (2017), Human Resource Management: Text and Cases, New Delhi: Tata McGraw-Hill Publishing Company Ltd.

Brown, P. (2004), Promoting work/life balance in a hurry culture: Issues and challenges. Griffith University Website: www.gu.edu.au/ins/collecions/proflects/brownp04.pdf

Clark, S. (2000), Work-family border theory: a new theory of work-life balance, Human Relations, Vol. 53, No. 6, pp. 747-770.

Greenblatt, E. (2002), Work-life balance: wisdom or whining, Organizational Dynamics, ol. 31, No. 2, pp. 177-193.

Hill, E.J., Hawkins, A.J., Ferris, M., and Weitzman, M. (2001), Finding an extra day a week: The positive influence of perceived job flexibility on work and family life balance, Family Relations, Vol. 50, No. 1, pp 49-63.

Limoges, J. (2003), A balanced work life: A matter of maintenance. Food for Thought Document 11, Ottawa: Canadian Career Development Foundation.

Opatha, H.H.D.N.P. (1994), Employee Grievance Settlement Procedure: A Case Study of Two Corporations, Management Review, Faculty of Management Studies and Commerce, University of Sri Jayewardenepura, Sri Lanka, Vol. 1, No.2, pp.53-60. 
Opatha, H.H.D.N.P. (2019), Sustainable Human Resource Management: Expanding Horizons of HRM, Colombo: Department of HRM, University of Sri Jayewardenepura.

Opatha, H.H.D.N.P. and Perera, H. (2017), Determinants of Work-Family Balance: An Empirical Study of Accounting Professionals in Sri Lanka, Sri Lankan Journal of Human Resource Management, Vol. 7, No.1, pp.18-34.

Senecal, C., Vallerand, R.J., and Guay, F. (2001), Antecedents and Outcomes of Work-Family Conflict: Toward a Motivational Model, PSPB, Vol. 27, No. 2, pp. 176-186.

Sturges, J. and Guest, D. (2004), Working to Live or Living to Work? Work/life balance early in the career, Human Resource Management, Vol. 14, No. 4, pp. 5-20.

Van, E.F.M. and Vos, J.P. (2002), Tautologies of work life balance, www.chaosforum.com/nieuws/Tautologies.pdf

\section{Appendix 1}

\section{The Interview Checklist}

1. As a manager the role you have to play is really vital in the company. It involves and demands a lot of responsibilities and tasks. So when considering with this situation, do you think it is important to have a balance between your work life and the family life?

2. Could you explain the reason behind your perception?

3. Have you ever faced with situations that you failed to maintain this balance?

4. What do you think or find as the causes for work-family conflicts?

5. Could you please explain how you maintain the balance between your work and family life? Explain the ways/your attempts to overcome these work-family conflicts you face.

6. Do you think that your immediate superior's attitude toward work and the support from him contribute to a greater extent in maintaining the work-family balance?

7. Please explain your views about the support from the family members (spouse, parents, children etc.) in balancing your work life and family life.

8. Do you think that the work stress and family stress complement with each other for the role you perform at work and at the same time in your family?

9. Please express your views about the females stretching out their boundaries and being employed. How do you feel about this dual role they play in the modern society? Would you encourage your spouse also to be employed? What is your perception about the effect that this cause would have on your work-family balance?

\section{Appendix 2}

The Questions and the Answers from the Manager numbered 1

1. As a manager the role you have to play is really vital in the company. It involves and demands a lot of responsibilities and tasks. So when considering with this situation, do you think it is important to have a balance between your work life and the family life? "Yes, it is absolutely important. There is no doubt about it. But I have to tell you that I am poor in fulfilling this obligation. I focus a lot on my professional life and my family life is mainly taken care by my wife." 


\section{Could you explain the reason behind your perception?}

"As a manager I have to perform a different role in the company. This involves a lot of field visits, and working at outstations. Therefore my work responsibility is very large. At the same time I could view myself as a very loyal employee to the company. Therefore I mainly put my fullest effort to satisfy the work related responsibilities than my family related ones. But on the other hand I know that work is not only the life. I have a different role to play at home. I am a father of one kid, and a good husband also. Therefore I am aware that I have to pay attention to their demands as well. But due to my loyalty towards my profession I most of the times fail in fulfilling my family related obligations, where my wife gives her fullest support to me in this area. All the credit should go to her. I would rather identify her as the success story behind my profession."

3. Have you ever faced with situations that you failed to maintain this balance?

"Yes I have. Especially in the circumstances such as that when I have to work for foreign assignments and outstation visits, then it has been very difficult for me to maintain the work-family balance. In such cases, it is totally the profession, not the family."

4. What do you think or find as the causes for work-family conflicts?

"I would find the primary cause as my work responsibility. And sometimes the poor understanding about my role by the family members also is a cause for the conflicts. Sometimes my spouse tries to compare me with my peers, which I see a cause for conflicts."

5. Could you please explain how you maintain the balance between your work and family life? Explain the ways/your attempts to overcome these work-family conflicts you face.

"As I told you earlier also, I think that I am poor in this area of maintaining the balance. But I think planning the tasks primarily is one key thing, would help anybody for this matter. But when I take myself I think that I am not $100 \%$ good in this. But there is a key role that I have to play in my family as the main figurehead. Therefore I somehow try to allocate my time for those matters. I try my level best to go home early. That is purely to give an understanding to my wife and my kid that I do concentrate on them too. Also at the same time, at least once a month I allocate time to go out with my family members to spend time leisurely. When I have extensive work duties to perform, I try to take my work home, and then do them from there."

6. Do you think that your immediate superior's attitude toward work and the support from him contribute to a greater extent in maintaining the work-family balance?

"Yes definitely this issue matters. Definitely my boss should be a person who has the ability to maintain the balance between his profession and the family. If he expects me to be a workaholic, then it is difficult for me to work. I have to tell you that here 
at ..........(the company name was deleted for anonymity purpose). We all in this division started from the very lowest level and reached where we are here today. Therefore I have never found my boss being influencing me in an adverse manner with this regard."

7. Please explain your views about the support from the family members (spouse, parents, children etc.) in balancing your work life and family life.

"My wife gives me an immense support in this regard. She gives her level best to create a peaceful mindset for me to come to the office and do my profession, which I think is very precious."

8. Do you think that the work stress and family stress complement with each other for the role you perform at work and at the same time in your family?

"Yes. I think that there is a relationship between these two. Personally I need to have a free mind set when it comes to family, for me to perform my duties and responsibilities at work successfully."

9. Please express your views about the females stretching out their boundaries and being employed. How do you feel about this dual role they play in the modern society? Would you encourage your spouse also to be employed? What is your perception about the effect that this cause would have on your work-family balance?

"This is good. I think those modern families are very smart to play this dual role. But my wife is not employed. She is a housewife, so I rather value her contribution and support given to me from this side than attempting to contribute to the family in financial means."

\section{The Questions and the Answers from the Manager numbered 7}

1. As a manager the role you have to play is really vital in the company. It involves and demands a lot of responsibilities and tasks. So when considering with this situation, do you think it is important to have a balance between your work life and the family life? "Yes, absolutely I think this is very important."

2. Could you explain the reason behind your perception?

"Purely I consider my job as a part of my life, and it is not my whole life. I have a family life too. Therefore I think that I need to have a balance between these two lives to avoid work-family conflicts."

3. Have you ever faced with situations that you failed to maintain this balance?

"Yeah, with the increasing responsibility I get I sometimes fail to maintain this balance. The balance between my work life and family life fluctuates. Say for an example towards the month end I have more concentration on my job rather than on my family matters." 
4. What do you think or find as the causes for work-family conflicts?

"One main cause is the improper understanding from the spouse and the other family members. On the other hand if you are a bad planner, and if you are not well organized then this itself could be a cause for the work-family conflcts."

5. Could you please explain how you maintain the balance between your work and family life? Explain the ways/your attempts to overcome these work-family conflicts you face.

"I think having a proper understanding about the different roles you have to play at different times helps to a greater extent in avoiding the work-family conflicts. Being able to manage the tasks within a limited time period, and the training to work for deadlines are also other two tactics which help a person to balance between work life and family life."

6. Do you think that your immediate superior's attitude toward work and the support from him contribute to a greater extent in maintaining the work-family balance?

"Yes this is something which all of the finance department members have faced and experienced. Earlier, our boss had very rigid rules and regulations to us that made most of us suffer mentally, and the same reason prevented us from maintaining the balance. But with the structural changes made to the company now we have a good support from out superior and therefore it has been a great help and an influence for us to balance our profession and family life."

7. Please explain your views about the support from the family members (spouse, parents, children etc.) in balancing your work life and family life.

"I get a great support from my parents. As my wife is employed too, my parents look after my kid. This helps me to come to work in a free mind. But at the same my wife's support even though she is employed is so important. I think that my wife is smarter enough to balance her profession and the family life than me."

8. Do you think that the work stress and family stress complement with each other for the role you perform at work and at the same time in your family?

"To a certain extent this is true. But I think that I have some capability of distinguishing between the professional stress and the family related stress. One must have the ability to manage both stresses."

9. Please express your views about the females stretching out their boundaries and being employed. How do you feel about this dual role they play in the modern society? Would you encourage your spouse also to be employed? What is your perception about the effect that this cause would have on your work-family balance?

"In a way it is good that the females are being employed. Personally I encourage my wife also to continue with her profession. But rather than to us, the family who has the lack of financial support and survival would think that both husband and wife being employed are very important. But at the same time I think that this also could 
affect the children's lives and their growth also. As far as I am concerned, my spouse's employment does not have a greater adverse impact on me in balancing my family and the professional life."

\section{The Questions and the Answers from the Manager numbered 15}

1. As a manager the role you have to play is really vital in the company. It involves and demands a lot of responsibilities and tasks. So when considering with this situation, do you think it is important to have a balance between your work life and the family life? "This is important. We need to maintain a balance between our professional live and the personal life."

2. Could you explain the reason behind your perception?

"If you don't strike a balance between your work and family it could create many conflicts, which ultimately result in poor mental health. Through this you will not be able to perform well in any area. I believe that one should have a steady mental background to perform well. Therefore having a better work-life management will help me."

3. Have you ever faced with situations that you failed to maintain this balance?

"Yes even at now I think that I am not balancing my life properly. To be frank, me being a female and being married for three years, I think that it is the correct time for me to give birth to a child. But due to the huge amount of work involvement I have with the company, this has been getting delayed day by day, where now only I'm thinking about this side of my life. Being a female and performing at the marketing field which is not an easy work I am late. Especially when working for a multi-national organization I have to engage in a lot of activities, but having come to this position, once I have climbed up my career only I realized that there is an area that I had not given attention to, where I am trying to allocate more time for it now."

4. What do you think or find as the causes for work-family conflicts?

"Main reason is not having an effort to maintain the correct balance. Considering about just one side of the coin is not enough. Even though you plan, sometimes I tend to plan only my professional life, but not the personal life when it comes to some issues."

5. Could you please explain how you maintain the balance between your work and family life? Explain the ways/your attempts to overcome these work-family conflicts you face.

"I am being honest with you here; I am not having a good balance right now. Especially my family demands have been neglected. But I think that listening to each other's demands in a family, then discussing about the problems we have at the profession as well as in the family would be really beneficial for maintaining the workfamily balance." 
6. Do you think that your immediate superior's attitude toward work and the support from him contribute to a greater extent in maintaining the work-family balance?

"Yes absolutely it has an effect, but at the same time we need to know about how to balance our own life. It is not only the superior's support."

7. Please explain your views about the support from the family members (spouse, parents, children etc.) in balancing your work life and family life.

"I get a very good support from my husband and in-laws. They have a good understanding about my professional demands and the role I play in the marketing field. Handling the 'power brands' of the company is not an easy task. Whenever I have to go outstation or out of the country, my husband has given me the fullest freedom to do so. Sometimes he too accompanies me on his own expense. This is a great support for me."

8. Do you think that the work stress and family stress complement with each other for the role you perform at work and at the same time in your family?

"The effect from the stress has a phenomenal relationship with the professional and family lives. As a female manager/manageress I think I need to have a good practice to handle the stress."

9. Please express your views about the females stretching out their boundaries and being employed. How do you feel about this dual role they play in the modern society? Would you encourage your spouse also to be employed? What is your perception about the effect that this cause would have on your work-family balance?

"A career woman needs to know to have a good balance. There is a vast responsibility lying on a female's hand. But if a woman thinks that she has the correct knowledge and the capacity, then there is no reason that she should limit herself into one end." 